\title{
Gratitude Mediates Consumer Responses to Marketing Communications
}

Reference: Bridger, E. K. \& Wood, A. M. (accepted). Gratitude mediates consumer responses to marketing communications. European Journal of Marketing.

Final version as submitted, pre-proofing, the copy of record and copyright reside with the journal.

\section{Author Note}

Emma K. Bridger, Division of Psychology, Faculty of Business, Law and Social Sciences, Birmingham City University.

Alex M. Wood, Behavioural Science Centre, Stirling Management School, University of Stirling.

Correspondence concerning this article should be addressed to Emma K. Bridger, Division of Psychology, Curzon Building (C335), 4 Cardigan St, Birmingham, B4 7BD. Email: emma.bridger@bcu.ac.uk 


\section{Abstract}

Purpose: From Adam Smith onwards, gratitude has been held as invaluable to societal functioning in view of its role in helping individuals maintain their reciprocal obligations to one another. The purpose of the current research was to use current conceptions of gratitude derived from work in social psychology to test whether simple descriptions of hypothetical organisations could systematically differ in the extent to which they elicit gratitude, and subsequently whether gratitude would mediate behavioural intentions towards these organisations.

Methodology: In two studies, participants read vignettes describing hypothetical organisations that systematically differed in the extent to which the services they provided were costly to the organisation, of high value, and provided out of a genuine desire to help. Perceptions of these dimensions, feelings of gratitude, and behavioural intentions towards each organisation were subsequently measured.

Findings: The appraisal group manipulation significantly impacted consumers' behavioural intentions towards these businesses, and the majority of this relationship was mediated by feelings of gratitude towards the organisations.

Research limitations/implications: These data indicate that gratitude not only mediates customer responses to relationship marketing investments, but may also be integral in marketing communications' role in converting non-customers to customers. They also indicate that marketing communications should stress that an organisations services are of high value, of cost to the organisation and provided out of a genuine desire to help.

Originality/value: This paper shows for the first time that the same cognitive appraisals that underpin feelings of interpersonal gratitude mediate responses to global evaluations of organisations. This considerably broadens the situations under which gratitude had previously 
been considered to operate and argues for the inclusion of gratitude in understanding how marketing communications and relationship management are used to influence consumer responses.

Keywords: Gratitude, Marketing communications, Relationship management, Relationship marketing, Cognitive appraisals, Value 


\section{Introduction}

In line with the shift towards focusing on the factors that assist the development of successful longitudinal relationships between businesses and consumers (Vargo and Lusch, 2004), marketing researchers now incorporate emotional components such as trust, commitment (Morgan and Hunt, 1994; Sirdeshmukh, Singh and Sabol, 2002) and - most recently - gratitude into relationship marketing (RM) models (Hasan, Lings, Neale, and Mortimer, 2014; Palmatier, Jarvis, Bechkoff and Kardes, 2009; Raggio, Walz, Godbole and Folse, 2014). Although the inclusion of gratitude in RM is recent relative to considerations of other relational components, it is now known to be fundamental to relational exchanges. This is in part, because gratitude is thought to be antecedent to other relational components such as trust and commitment, making it vital to the initiation of successful business-to-consumer (B2C) relationships (Raggio et al., 2014), but also because it is critical for the successful maintenance of these relationships given its role in encouraging individuals to reciprocate positive behaviours from which they have benefited (Palmatier, 2008).

These modern reflections echo Adam Smith's (1790/1976) original analysis of gratitude, in which he argued that it is essential for societal functioning because it provides a non-utilitarian basis for individuals to maintain their obligations to one another. Almost all of the psychological literature into gratitude has only developed in the last few years (Wood, Froh, \& Geraghty, 2010), but in line with this fundamental assumption, psychological data shows that feelings of gratitude predict the reciprocation of altruistic acts (Bartlett and DeSteno, 2006). Within commercial contexts, self-reported gratitude mediates the pathway between consumers' responses to RM investments (e.g. when a seller makes additional effort such as including favours or gifts, adapting policies or personalising interactions) and their intentions to purchase from the company that made said investment. In one of the first studies of this kind, Palmatier and colleagues (2009) manipulated factors designed to influence 
responses to an RM investment, such as the seller's free will and motives when making the investment, using hypothetical vignettes in which an employee at a clothing store ('Alex') offered help to the respondent. Feelings of gratitude, trust, commitment and purchase intentions were measured subsequently. Feelings of gratitude mediated the relationship between perceptions of RM investments and consumer purchase intentions. The mediational role of gratitude was also found to extend to longitudinal field data: Customer gratitude-based reciprocal behaviours predicted sales revenue and sales growth for data from 31 North American manufacturers' representative firms (Palmatier et al., 2009). Combined, the implications from this work are to emphasise the importance of understanding and increasing consumer gratitude in order to maximise RM investment outcomes.

A crucial approach to fully understanding gratitude's role in commercial contexts is to incorporate psychological models of the cognitive mechanisms that underpin feelings of gratitude. The social-cognitive model of gratitude seeks to achieve this by addressing the situational factors and associated appraisals that determine the extent to which gratitude is experienced in a given situation (Wood, Maltby, Stewart, Linley and Joseph, 2008).

Critically, the model states that this depends upon a series of attributions individuals make about the nature of the aid that they receive. Building on work by Tesser, Gatewood and Driver (1968), the model asserts that gratitude rests on perceptions of three aspects of the situation: (a) the benefactor's cost of giving aid (b) the value of the aid given to the recipient and (c) the intention of the benefactor, in particular whether they appear to be altruistically motivated as opposed to being driven by ulterior motives. Across two experiments, Wood et al. show that these three evaluations reflect a single latent construct, hereafter termed a benefit appraisal. In a further study, benefit appraisals were manipulated in vignette-descriptions of situations in which aid was received and it was shown that these benefit appraisals have a causal effect on state gratitude. 
According to the social-cognitive model of gratitude therefore, gratitude should be elicited whenever individuals perceive a benefactor's action; (i) to be of high cost to the benefactor, (ii) to bestow benefits that are of high value, and (iii) implemented out of a genuine desire to help. Although not set in the exact terms of the benefit appraisal model, the dimensions employed by Palmatier et al. (2009) to manipulate perceptions of RM investments, in particular the seller's free will and motives and the customer's needs for RM investment outcomes, tally with the three facets of a benefit appraisal, and supports the application of this model to commercial and RM contexts. The novel emphasis of the current paper, however, is a more thorough application of the social-cognitive model of gratitude to consumer behaviour, in particular the consideration that gratitude-eliciting cognitive appraisals operate when consumers initially encounter descriptions of businesses, and that these appraisals may mediate consumers' intentions to act positively towards organisations, even when they are not the direct recipients of an RM investment.

Previous indications that consumer gratitude can operate prior to direct interactions with businesses come from Morales (2005), who manipulated the effort that a hypothetical service provider made whilst displaying their products. Effort increased positive ratings of the service provider and this relationship was mediated by feelings of gratitude and indebtedness. More recent work by Raggio \& Folse $(2009,2011)$ has shown that exposure to expressions of gratitude from post-Katrina Louisiana residents has a positive impact on perceptions of Louisiana from other US residents. Findings of this kind underscore the critical role of expressions of gratitude in the successful development of relational exchanges between business and customer, and the commonly understood notion that gratitude should not only be felt, but also expressed (Raggio et al., 2014). It is important to note, however, that the current work seeks to determine the role of gratitude at the earliest stage of a consumer's consumption journey - when first encountering a description of a company. 
The studies reported here comprise more direct tests of the hypothesis that gratitude can be elicited by simply reading a description of a company, and that this is the psychological mechanism by which consumers' appraisals relate to their intentions towards businesses. If gratitude is found to mediate consumers' responses to messages of this kind, this would highlight a role for gratitude in consumer responses to more global depictions of commercial organisations, such as are typically managed by public relations and marketing public relations practitioners (Kitchen and Papasolomou, 1997; Papasolomou, Thrassou, Vrontis \& Sabova, 2014) in order to manage organisation-public relationships (Ledingham, 2003). Ultimately, this would constitute a much earlier-occurring and more pervasive role for gratitude in consumer responses to marketer actions than previously considered.

\section{Study 1}

The impact of benefit appraisals elicited by global descriptions of organisations on gratitude and behavioural intentions towards these same organisations was tested in Study 1. Two descriptions of six hypothetical yet realistic organisations were created so that they differed in the extent to which they depicted services that are costly, valuable and offered out of a genuine desire to help. Participants read one version of each of the six vignettes (high vs. low benefit appraisals) and were asked to rate their perceptions of these three appraisal variables, their gratitude towards each organisation and their behavioural intentions (i.e. how willing they were to recommend each organisation). If the appraisal group manipulation was successful, then benefit appraisals (perceptions of cost, value and genuine desire to help) should be higher in the high than the low appraisal condition. The principal model under examination, however, was that the appraisal group manipulation would influence behavioural intentions, and that this pathway would be mediated by gratitude. 


\section{Method}

\section{Participants}

Potential respondents were invited to complete an online survey on evaluations of different organisations, advertised as taking no longer than 10 minutes. Invitations were hosted on the University of Stirling's staff and student homepage as well as via social media sites. Ninety-five participants consented to take part in the survey but 8 did not reach the end of the survey. All data are described for the remaining 87 participants. Participants fell into a variety of age groups; 15 were 18-24 years old; 52 were $25-34$ years old; 13 were 35-44 years old; 2 were 45-54 years old; 4 were 55-65 years old and 1 participant was over 65 . Seventysix percent of the sample reported themselves as coming from the UK with the remainder from Germany, Turkey, USA, France, Switzerland, Ireland, Norway, Australia and Argentina. Random allocation yielded 42 participants in the high appraisal condition (16 male, 26 female) and 45 in the low appraisal condition (24 male, 21 female). A chi-square contingency test revealed no significant association between gender and appraisal group condition $\left(\chi^{2}(1, N\right.$ $=87)=2.03, p>.154)$.

\section{Materials and Procedure}

The key materials (presented in Appendix A) were six short descriptions of hypothetical organisations. In order to include a variety of organisations, three of the vignettes described businesses whereas the remainder were labelled as charities, and organisation-type was included as a factor. In all cases, the vignettes were comprised of four sentences, the first of which was identical across the two appraisal group conditions, whereas the final three sentences differed for the two conditions. The second sentence manipulated perceived value; the third manipulated genuine desire to help whilst the fourth sentence manipulated cost. 
Appraisals were manipulated in this way because prior work has shown that these factors represent the same latent construct, whilst the critical question of interest is whether this construct (benefit appraisal) has an impact on gratitude and intentions towards organisations (see Wood et al., 2008 for similar logic).

Both studies reported in this paper were approved by the School of Management Ethics Committee. Upon giving their consent, participants were presented with a series of six vignettes describing hypothetical organisations in randomised order. Upon reading each, participants were asked to answer seven questions. The first three questions were taken from Zeithaml, Berry and Parasuraman (1996) and are designed to assess behavioural intentions towards each organisation. The three questions are; "How likely is it that you would say positive things about this organisation to other people?", "How likely is it that you would recommend this organisation to someone who seeks your advice?", and "How likely is it that this organisation would be your first choice for services of this kind?”. Participants responded on a 1-6 scale where 1 = "very unlikely" and 6 = "very likely".

The final four questions assessed perceptions of genuine helpfulness, perceived cost, perceived value, and gratitude towards each organisation. All four questions were adapted from Wood et al. (2008). Genuine helpfulness was measured by asking "How much do you think that this organisation are motivated by a sincere desire to help?" using a 1-6 scale where $1=$ "not at all motivated" and $6=$ "totally motivated". Perceived cost was measured by asking "How much do you think it costs this organisation to provide the services it provides (in terms of time, effort, financial cost etc.)?" using a 1-6 scale where $1=$ "nothing" and 6 = "a great deal". Perceived value was measured by asking "How valuable do you think are the services that this organisation provides?" using a 1-6 scale where $1=$ "not at all valuable" and $6=$ "extremely valuable“. Finally, gratitude was measured by asking, "How much gratitude do you feel towards this organisation?" using a 1-6 scale where $1=$ "no gratitude" and $6=$ "a lot 
of gratitude“. Participants were asked to give their age, gender and nationality at the end of the survey. Upon completing their demographic details, participants were given the opportunity to provide feedback on the survey. These data are not explicitly analysed here, although some responses were taken into account when designing Study 2 (see Study 2 Method).

\section{Design and Analysis Strategy}

A $2 \times 2 \times 3$ mixed design with between-subjects factors of appraisal group (high vs. low) and within-subjects factors of organisation-type (charity vs. business) and vignette (3 levels) was used. The three behavioural intentions measures were shown to be strongly associated with each other ("say positive things?" and "would you recommend?"; $r=.94, p<.001$; "say positive things?" and "first choice for services of this kind?"; $r=.89, p<.001$; "would you recommend?" and "first choice for services of this kind?"; $r=.93, p<.001$, all $\mathrm{n}=87$ ), and the associated Cronbach's alpha was excellent $(\alpha=.97)$. A single measure was subsequently derived using the average response to all three items.

The first step of the analysis began with a manipulation check to determine the impact of the appraisal group manipulation on benefit appraisals (perceptions of cost, value and genuine desire to help). This was tested using a 2x2x3 MANOVA with the factors outlined above, on the three dependent variables. Main effects of appraisal group would indicate that the manipulation successfully influenced the core perceptions that drive gratitude.

Demonstrating this licensed the second set of analyses, which was the test that gratitude mediates the relationship between the appraisal group manipulation and behavioural intentions. According to Baron and Kenny (1986) three regression equations can be used to establish mediation. Step one requires demonstrating that the independent variable (appraisal group) has a direct impact on the mediating variable (gratitude). Step two requires the 
demonstration that the independent variable impacts on the dependent variable (behavioural intentions). Step three is fulfilled when it is shown that the mediator impacts on the dependent variable when the dependent variable is regressed on both the mediator and independent variable. Assessment of the significance of the indirect effect of appraisal group on behavioural intentions (via gratitude) was tested using Sobel's test (1982). For all relevant analyses, the appraisal group manipulation was coded as follows: low $=0$ and high $=1$.

The third step of analyses were moderation analyses, conducted to determine whether the organisation-type factor moderated any of the pathways from appraisal group to behavioural intentions. For each pathway, the dependent variable was regressed onto the predictor, the moderator (organisation-type: $1=$ business, $2=$ charity) and an interaction variable (created by multiplying the predictor by the moderator). In order to avoid multicollinearity between predictor and interaction terms, Aiken and West (1991) recommend centring continuous predictor variables. Gratitude, as the only continuous predictor, was thus grand mean centred for the corresponding analysis. A significant effect for the interaction variable would indicate moderation had occurred and that the role of gratitude differed for different kinds of organisation.

Critically, however, analysis steps two and three (mediation and moderation) were both tested by converting the data to long format and running mixed-model analyses (specifically: restricted maximum likelihood, which is preferred for smaller sample sizes). Mixed-models allow for both fixed and random effects to be specified, in which fixed effects refer to standard effects most familiar to standard OLS regression-users (and are thus reflected in the coefficients reported), whereas random effects take account of betweenindividual variance because they can vary across all individuals in a sample. This is necessary for the current data in order to conduct regression-like analyses which allow a within-subjects variable (in this case, organisation-type) to be included in and able to interact with an 
individual-subject level predictor (in this case, the appraisal group manipulation) but without violating the assumption of independence (Hoffman and Rovine, 2007). Including random effects for individual subjects, is necessary, therefore in order to provide accurate parameter estimates, to ensure the model clusters non-independent error terms at the appropriate levels and to allow conclusions to be drawn across different levels of the population structure (Snijders, 2005). For both the mediation and moderation analyses, therefore, random intercepts were included in the model for individual subjects and for the factor organisationtype, nested within subjects. This model was re-specified for each of Baron and Kenny's steps to establishing mediation as well as for subsequent moderation analyses, with a different predictor (or predictors) of interest in each case, to be modelled as the corresponding fixed effects. Unstandardized coefficients, as are typically estimated by multi-level models of this kind, are reported throughout (Nezlek, 2001).

\section{Results}

[Figure 1 to be inserted around here]

Manipulation Check: Perceived desire to help, cost, and value

Figure 1 depicts mean perceptions of genuine desire to help, cost and value for the critical conditions. Perceptions of all three measures appear sensitive to the appraisal group manipulation. For perceptions of cost this pattern appears constant across all 6 vignettes, whereas for perceived value it is largest for two of the business vignettes and generally smaller for the three charity scenarios. Ratings of perceived desire to help, were generally higher for the three charity scenarios, and the appraisal manipulation was most robust for these vignettes. This pattern was tested by subjecting ratings of desire to help, cost and value to a 2 (appraisal group: high/low) x 2 (organisation-type: business/charity) x 3 (vignette: 3 
levels) mixed MANOVA and subsequent univariate analyses. The outcomes of these analyses are shown in Table 1.

[Table 1 to be inserted around here]

Main effects of appraisal group and organisation-type were observed for all measures, reflecting higher ratings for the high than low appraisal group and charities than businesses. The main effect of vignette also indicates higher overall ratings for some vignettes than others as would be expected given the use of a diverse range of realistic organisations. Two- and three-way interactions including the appraisal group factor indicate, that the impact of this manipulation differed in size for particular vignettes and organisation-types. To explicate this, independent $t$-tests (Bonferroni-corrected $p=.008$ ) and associated effect sizes are reported to demonstrate the impact of the benefit-appraisal manipulation on each vignette for each of the three variables. These are reported in Table 2, which shows that perceived desire to help was significantly higher in the high than low appraisal group for all six vignettes. For perceived value, the appraisal group manipulation was significant for all vignettes except To The Moon and Billesley Restorations. For perceived cost, the manipulation was successful at influencing perceived cost for all six vignettes but effect sizes reveal impact was largest for Dogs Down Under.

[Table 2 to be inserted around here]

These analyses reveal two points to note. Firstly, the main effects of appraisal manipulation and organisation-type show higher perceptions of all three outcomes for the high than low appraisal group as well as for charities relative to businesses. Secondly, the 
appraisal manipulation was effective to differing extents for particular vignettes and appraisal features: For perceived value, the manipulation was greatest for two of the three business vignettes (Hawkival/Permasole), but less so for the charities, in part because perceptions of value were relatively high for these vignettes even in the low appraisal group. These outcomes reveal the success of the appraisal group manipulation on benefit appraisals, as well as the importance of taking account of the moderating impact of particular vignette features on benefit appraisals and associated gratitude.

\section{Testing the Mediation Model}

The principal model under investigation tests whether gratitude mediates the relationship between the appraisal manipulation and behavioural intentions. This was tested using Baron and Kenny's (1986) three regression equations to establish mediation. In line with step one, the appraisal group manipulation had a significant impact on gratitude, the mediator $(b=1.03$, standard error $=.19, t(85)=5.50, p<.001)$. In line with step two, the appraisal group manipulation had a significant impact on the outcome variable, behavioural intentions $(b=1.41, \mathrm{SE}=.17, t(85)=5.52, p<.001)$. Critically, in line with the final requirement for mediation, gratitude was found to significantly predict behavioural intentions $(b=.59, \mathrm{SE}=.03, t(361)=21.49, p<.001)$ whilst the impact of appraisal group decreased but remained significant $(b=.81, \mathrm{SE}=.12, t(93)=6.73, p<.001)$. Sobel's $(1982)$ test indicated that the indirect pathway from appraisal group through gratitude to behavioural intentions was significant $(z=5.27, p<.05)$. Calculations using the squared beta values indicated that gratitude mediated $67 \%$ of this pathway. Together, these data show that feelings of gratitude partially mediate the impact of benefit appraisals on behavioural intentions.

\section{Testing for Moderation}


The preceding analyses reveal both a significant direct and indirect pathway from the appraisal manipulation to behavioural intentions. In the final step, these pathways were tested to see whether the size of the effect differed across organisation-type, which would be shown by a significant interaction term. For the direct pathway from appraisal manipulation to behavioural intentions, the interaction term was significant $(b=-.51, \mathrm{SE}=.17, t(433)=-$ $3.023, p<.01)$, as were the main effects of appraisal manipulation $(b=2.18, \mathrm{SE}=.30, t(459)=$ $7.18, p<.001)$ and organisation-type $(b=1.05, \mathrm{SE}=.12, t(433)=8.88, p<.001)$. There was no evidence that organisation-type moderated the pathway from appraisal manipulation to gratitude ( $p=.615)$. For the path from gratitude to behavioural intentions, the gratitude $\mathrm{X}$ organisation-type interaction term significantly predicted behavioural intentions $(b=-.17, \mathrm{SE}$ $=.05, t(254)=-3.22, p<.01)$, and gratitude continued to impact behavioural intentions $(b=$ $.91, \mathrm{SE}=.09, t(481)=9.78, \mathrm{p}<.001)$. There was no main effect of organisation-type $(p=.170)$.

Together, these outcomes indicate that organisation-type moderated the direct pathway within the model as well as the second step of the indirect path from gratitude to behavioural intentions. This was tested in a final model in which behavioural intentions were regressed onto appraisal manipulation (predictor 1), gratitude (predictor 2), organisation-type (moderator) and the interaction terms between the two predictors and moderator term. The two predictors remained significant (appraisal group, $b=1.53$, $\mathrm{SE}=.25$; gratitude, $b=.72$, $\mathrm{SE}$ $=.10$, both $p$-values<.001), whereas only the appraisal group $\mathrm{X}$ organisation-type interaction term was significant $(b=-.49, \mathrm{SE}=.15, \mathrm{p}<.01)$. The negative interaction term indicates that the impact of the appraisal manipulation on behavioural intentions was less for charities (coded as 2) than for businesses (coded as 1). The outcomes of these analyses are depicted in Figure 2.

[Figure 2 to be inserted around here] 


\section{Brief Discussion}

Study 1 showed that the extent to which an organisation was described as providing services high in value, high in cost to the organisation and provided out of a genuine desire to help had a significant impact on behavioural intentions, and this effect was mediated by gratitude. The data also indicated that benefit appraisals were more positive for some vignettes than others, as would be expected given the variety of organisations employed. The moderation analyses, however, revealed that the impact of the appraisal group manipulation on behavioural intentions was moderated by the factor organisation-type. Although an interaction of this kind might indicate that low benefit appraisals could be particularly damaging to some kinds of organisations, claims of this kind are limited in Study 1 because the scenarios associated with charities and businesses differed in a number of ways that may also have impacted on benefit appraisals, beyond the charity vs. business label. Study 2 was designed to provide a stronger test of the possibility that the impact of benefit appraisals might be larger for charities vs. businesses by manipulating only the organisation label and controlling all other aspects of the organisation descriptions.

\section{Study 2}

Study 2 was conducted to replicate the mediational role of gratitude in the impact of global benefit appraisals on behavioural intentions, shown in Study 1. Study 2 was also designed to determine whether the moderating role of organisation observed in Study 1 was a systematic effect of the label business vs. charity or driven by the characteristics of the particular organisations. All participants read and rated two vignettes, one labelled as a business and the other as a non-profit organisation. The latter term was preferred over the label "charity" used in Study 1 because, as a more generic term, it should be easier to 
convincingly apply it across organisations. Organisation-type was thus manipulated withinsubjects, whilst appraisal group remained manipulated orthogonally across participants.

\section{Methods}

\section{Participants}

These were invited to complete an online survey on evaluations of different organisations advertised as taking no longer than 5 minutes. Seventy-one participants clicked on the survey but 4 did not reach the end of the survey. All data is described for the remaining 67 participants. The age range of the final sample was 19-66 with a mean of 34 years. The majority of the sample identified as White $(85 \%)$ with the remainder identifying as Asian (9.0\%), Latin/Hispanic (3.0\%) or Black (1.5\%; 1 participant withheld their response). Thirtyfour participants were randomly allocated to the high appraisal group ( 22 female, 11 male, 1 transgendered) and 33 were allocated to the low appraisal group (18 female, 15 male). A chisquare contingency test revealed no significant association between gender and appraisal $\operatorname{group}\left(\chi^{2}(2, \mathrm{~N}=67)=2.00, p>.368\right)$.

\section{Design and Materials}

Two vignettes (one charity, one business) used in Study 1 were selected for use in Study 2. Hawkival and African Cooperatives were selected because effect sizes were robust across the three benefit appraisal outcomes (see Table 2) and it was thought that these vignettes could best lend themselves to either a business or non-profit context. The vignettes were modified so as to make them both more plausible with identification as either a business or a non-profit organisation, and the names were shortened to increase comparability (see Appendix B). "Hawkival" was changed to "Hawklin" because participant feedback (collected upon completion of the questionnaire in Study 1) indicated that low scores may have been 
given for this organisation because this name was judged particularly negatively. Thirty-two participants saw the Hawklin labelled as a business whilst AfriCo was labelled as a non-profit organisation, whilst for the remaining 35 participants, the allocation of vignette (Hawklin/AfriCo) to organisation-type (business/non-profit organisation) was reversed. This between-groups factor is a counterbalance measure and analyses are collapsed across this factor. The final design was thus mixed $2 \times 2$ with a between-subjects factor of appraisal group (high vs. low) and a within-subjects factor of organisation-type (business vs. non-profit organisation). The analysis strategy followed that employed in Study 1: an initial manipulation check, followed by tests of the mediation and moderation models using mixedmodels analyses.

\section{Procedure}

After giving their consent, participants were presented with the two vignettes. Participants were asked the same questions employed in Study 1, with the exception that they were no longer asked to what extent each organisation would be their first choice for services of this kind. This was removed because participants indicated that it made little sense to them in the current context and correlated with the other two behavioural intentions measures to a lesser degree. Upon completion of these responses, participants were asked to complete the GQ-6 scale ${ }^{1}$ of trait gratitude (McCullough, Emmons and Tsang, 2002), as well as give their age, gender and ethnic identity.

\section{Results}

[Figure 3 to be inserted around here]

\footnotetext{
${ }^{1}$ This was measured in order to explore supplementary hypotheses concerning the impact of trait gratitude on benefit appraisals as well as gratitude and behavioural intentions. No interactions were observed, however, and the impact of trait gratitude in Study 2 is not reported further.
} 
Manipulation Check: Perceived desire to help, cost, and value

Figure 3 depicts mean perceptions of genuine helpfulness, cost and value for the critical conditions, and shows that the effect of the appraisal manipulation appears for both organisation-types, across all three variables. This was tested by subjecting perceived cost, value and desire to help to a 2x2 mixed MANOVA and subsequent univariate analyses with between-subjects factor of appraisal group (high vs. low), and the within-subjects factor of organisation-type (non-profit vs. business). The outcomes of these analyses are shown in Table 3. Main effects of appraisal group were observed for all measures. There was no main effect of organisation-type, however, and the interaction between appraisal group and organisation-type was significant only for perceived cost.

[Table 3 to be inserted around here]

The interaction for perceived cost between appraisal group and organisation-type was deconstructed using follow-up contrasts (Bonferroni-corrected $p=.0125$ ) which revealed a significant effect of appraisal group on business $(d=1.43, p<.001)$ but not on non-profit organisations. The effect of organisation-type was significant for the high $(d=.44, p<.01)$ but not low benefit appraisal condition. This pattern indicates that the appraisal group manipulation was only successful in manipulating perceived cost for businesses, and that participants in the high appraisal condition rated perceptions of cost to be particularly high for the business vignettes. 
The absence of interactions between appraisal group and organisation-type for perceived value and perceived desire to help ${ }^{2}$ indicate that the organisation label did not have a systematic impact on these appraisals when all other factors were controlled. This outcome indicates that where there was evidence of a differential impact of the appraisal manipulation in Study 1, this was driven by features of specific vignettes rather than whether organisations were labelled as business or non-profit.

\section{Testing the Mediation Model}

The three steps of the mediation model were again tested using the same approach as in Study 1. A restricted maximum likelihood linear mixed-model was employed with subjects' individual intercepts modelled as, and the predictor for each step employed as fixed effect. Appraisal group had a significant impact on gratitude $(b=.97, \mathrm{SE}=.33, t(65)=2.98$, $p<.01)$, and a significant impact on behavioural intentions $(b=1.54, \mathrm{SE}=.25, t(65)=6.25$, $p<.001)$ in line with Baron and Kenny's steps one and two. In the final step, gratitude significantly predicted behavioural intentions $(b=.62, \mathrm{SE}=.05, t(130)=12.32, p<.001)$ whilst the impact of appraisal group on behavioural intentions decreased $(b=.94, \mathrm{SE}=.19$, $t(67)=4.97, p<.001)$. Sobel's test indicated that the indirect pathway from appraisal group through gratitude to behavioural intentions was significant $(z=2.87, p<.001)$. Calculations using the squared betas show that gratitude mediated $63 \%$ of this pathway.

\section{Testing for Moderation}

\footnotetext{
${ }^{2}$ We note that when these analyses were conducted with the counterbalance version as an additional two-level factor (i.e. AfriCo as business vs. AfriCo as non-profit), there were 3-way interactions between appraisal group, organisation-type and counterbalance version for perceived desire to help $(\mathrm{F}(1,61)=12.60, \mathrm{p}<.01)$ and perceived value $(\mathrm{F}(1,61)=23.64, \mathrm{p}<.001)$. Follow-up analyses of these outcomes, however, revealed that these interactions were driven exclusively by the vignettes themselves regardless of the organisation label given (specifically, the Hawklin vignette was more sensitive to the appraisal manipulation regardless of whether it was labelled business or non-profit, whereas AfriCo was less sensitive regardless of organisation label). Given that these analyses are complex and do not provide any additional insight beyond confirming that organisation label does not interact with appraisal group, we do not further report them here.
} 
The univariate analyses above indicate that individual characteristics of the particular vignettes rather than the organisation label impacted benefit appraisals, at least for perceived value and perceived desire to help. To provide a final test of whether organisation label systematically moderates the impact of the appraisal manipulation on behavioural intentions, a final set of moderation analyses identical to those employed in Study 1 were conducted. Again, for each pathway, parameter estimates were derived using a multilevel model including the predictor variable, the moderator $(1=$ business, $2=$ non-profit $)$ and an interaction variable created by multiplying the predictor by the moderator. In each case, the interaction term was not significant (both $p>.243$ ). There was thus no evidence that the impact of the appraisal manipulation on behavioural intentions in Study 2 was moderated by organisation-type. Figure 4 shows the outcomes of the mediation model from Study 2.

[Figure 4 to be inserted around here]

\section{Brief Discussion}

Study 2 fully replicated the principal outcome from Study 1: that appraisals impact consumer intentions towards organisations and that this pathway is partially mediated by feelings of gratitude. Study 2 further demonstrated that any moderation of the impact of appraisal group on behavioural intentions was not a consequence of whether organisations were labelled as a business or non-profit organisation. The exception to this pattern was in perceptions of cost, which did differ for organisation-type, and which indicates that some types of business may be viewed as inherently high in cost. Important to note, however, is that the impact of the combined appraisal group manipulation on intentions via gratitude was not moderated by organisation-type. The implications of positive and negative benefit appraisals thus apply equally to non-profit and profit-driven enterprises. Where differences were 
observed in Study 1, therefore, this presumably reflects the fact that some services will always be perceived to have an inherently high value, no matter how this is framed. Other business ventures, however, may be especially vulnerable to negative framing.

Combined, the data from Study 1 and 2 demonstrate that benefit appraisals operate when individuals make global evaluations of companies and that these appraisals can influence consumers' intentions towards businesses. This thus demonstrates that benefit appraisals can impact gratitude even when respondents are only reading a description of a company, extending the contexts in which situational factors have been shown to influence gratitude previously (Wood et al., 2008c). Critically, the current data show for the first time that gratitude, a fundamental social emotion heretofore unstudied in this context, is the mechanism through which evaluations of this kind operate, when individuals first encounter company descriptions.

\section{General Discussion}

The same benefit appraisals that elicit interpersonal feelings of gratitude were shown to also apply when individuals read global descriptions of organisations. Gratitude was shown to be the mediating mechanism by which these appraisals drive consumer intentions towards businesses. This pattern was robust across the two studies and was found to apply across organisations regardless of whether they were labelled as businesses or non-profit organisations. These data place a previously overlooked yet fundamental social emotion at the heart of understanding consumer responses to marketing communications. In the following sections, we discuss the implications of this for various areas of marketing, communication and public relations.

\section{Gratitude in Relationship Management}


Management of organisation-public relationships forms the basis of modern public relations (Ledingham, 2003) and theoretical perspectives of public relations look to determine those factors key to positively managing and sustaining these relationships. By scaling up understanding of interpersonal communication to inform how organisations can effectively communicate with individuals in the public, the relational perspective in public relations has followed a similar trend to that of marketing (Jahansoozi, 2006), and trust, openness, and commitment have been acknowledged as important dimensions by both relationship management practitioners (Ledingham and Bruning, 1998) and relationship marketers (Sirdeshmukh et al., 2002). At the same time, however, whilst the role of gratitude in characterising consumer responses to RM investments has already been shown (Palmatier et al., 2009) this is the first demonstration for a role for gratitude in consumer responses to initial marketing communications.

Organisation-public relationships can be viewed at either behavioural or symbolic levels (Grunig, 1993), the former encompassing organisation actions, which would include RM investments, whereas symbolic relationships are principally communication-based. Successful relationship management, however, requires incorporation of both levels (Ledingham and Bruning, 1998). The data presented here show that gratitude's role in influencing and understanding consumer responses to relationship management strategies extends from the behavioural to the symbolic and communications level.

\section{Gratitude, Satisfaction and Perceived Value}

One of the core appraisal dimensions upon which gratitude has been shown to rest, is value to the recipient. Providing products and services that elicit high levels of perceived value has long been recognised as integral to relationship marketing, given that customer satisfaction is dependent on perceived value (Ravald and Grönoss, 1996). Considerable focus 
has thus come to bear on how to increase perceived value and engage value-adding strategies to increase customer satisfaction by both maximising benefits to customers whilst limiting any financial or behavioural costs to them (Monroe, 1991; Ravald and Grönoss, 1996). By demonstrating that perceived value is also core to feelings of gratitude, it is shown that valueadding strategies should also serve to increase gratitude and in turn drive consumer behaviour towards organisations. Given the degree of overlap between consumer satisfaction and gratitude, it may be valuable to clarify the arguments for marketers to consider gratitude alongside of rather than instead of satisfaction. Firstly, whilst satisfaction hinges on the value to the recipient, which is an evaluation of benefits received relative to costs outlaid, gratitude is determined by benefits received (measured as "perceived value" here) alongside appraisals of the costs to and motives of the benefactor. Secondly, satisfaction is assumed to succeed high service quality and perceived value (Parasuraman, Zeithaml and Berry, 1988) and as such cannot be an antecedent to the development of a business-to-consumer relationship. Showing that appraisals play a role when consumers' evaluate organisations as a whole before they engage directly with a business may mean that appraisals and gratitude could predict customer acquisition or initial engagement with businesses. Gratitude may therefore be the psychological mechanism through which marketing communications achieve their principal goal of converting non-customers to customers (Hart, 1995).

\section{Gratitude, Public Relations and Social Responsibility}

One clear implication that arises from the current perspective is the value to organisations to be seen to provide services that (i) are of high value, (ii) costly to the provider and (iii) provided out of a genuine desire to help. That the public should perceive organisations as forces operating in the public interest has long been recognised as fundamental to public relations theory (Grunig \& White, 1992) given that the norm of 
reciprocity determines whether the public will respond positively or negatively to an organisation (Gouldner, 1960; Grunig \& White, 1992). Here, we highlight the psychological mechanism and associated cognitive appraisals by which these perceptions are likely to translate to goodwill towards organisations, provided that corporate activities are perceived as positive, costly and genuine. Perhaps the most obvious example of services explicitly designed to meet criteria of high value, demonstrating an altruistic desire to help at cost to the provider are corporate social responsibility (CSR) practices; voluntary projects undertaken in and for the benefit of the wider community outside an organisation's primary domain (L'Etang, 1996). CSR practices are particularly interesting because they highlight inherent tensions that arise when PR operations are employed to showcase an organisation's efforts towards serving the public interest whilst principally operating to advocate that same organisations' own interests (L'Etang, 1996; Fleming \& Jones, 2013). There are strong and compelling reasons for individuals to question organisations' motives in adopting CSR practices (Fleming \& Jones, 2013). Highlighting that consumers' positive intentions towards organisations are likely to rest on the extent to which services are perceived to be provided out of a genuine desire to help as opposed to serving ulterior motives, would suggest that CSR initiatives will remain limited in their effectiveness, so long as such cynicism remains. We note that a similar challenge in promoting perceptions of genuine sincerity is inherent for practitioners when using marketing communications for publicity campaigns.

\section{Limitations}

Some aspects of the data from Studies 1 and 2 do not align entirely with the initial model tested. Participant ratings of perceived cost to organisations, for example, did not consistently match the pattern of responses to perceived value and desire to help. This may reflect a weaker association between appraisals of cost and gratitude when individuals 
evaluate services provided by organisations, perhaps because services are always likely to bestow a cost of some kind. The pattern reported here, however, does to some extent tally with that shown for interpersonal vignettes: Wood et al. (2008) reported smaller associations between state gratitude and cost appraisals than for perceived value and genuine helpfulness, and the manipulation of risk (i.e. potential cost) to benefactor used by Palmatier et al (2009) was unsuccessful. A rethink of the role of cost appraisals is problematic, however, for the theoretical position that, as a regulator of reciprocal altruistic acts whose adaptive value is dependent upon their cost/benefit ratio, gratitude is fine-tuned to considerations of cost as well as benefit (Trivers, 1971). More precise determination of the antecedents of gratitude will thus require closer analysis of the role of cost appraisals.

One further limitation is that the current approach is limited in the extent to which the appraisal manipulation can be attributed to relative increases or decreases in evaluation, given that no baseline condition was employed. Put another way, it is not possible to determine whether the current effects are driven by increases in gratitude for high appraisals or punishing evaluations for what is viewed as particularly poor service. One candidate mechanism that might cause consumers to punish organisations on the basis of particularly low evaluations is resentment, the sentiment Smith (1790/1976) posited as the antagonist to gratitude and a key driver of punishment. Further work should seek to determine the extent to which rewarding vs. punishing actions are driven by distinct affective mechanisms as opposed to different ends of the same affective continuum, perhaps by including a third "neutral" baseline appraisal group condition.

\section{Conclusions}

By considering the fundamental cognitive components upon which feelings of gratitude rest, the current model places this highly influential social emotion as a mechanism 
behind consumer responses to simple descriptions of a company, prior to any direct interaction with a company. These findings have clear implications for the importance of ensuring value, cost and genuine desire to help are coherently communicated within relationship management campaigns. 


\section{References}

Aiken, L. S., and West, S. G. (1991), Multiple regression: Testing and interpreting interactions. Newbury Park, CA: Sage.

Baron, R. M. and Kenny, D. A. (1986), "The moderator-mediator variable distinction in social psychological research: Conceptual, strategic, and statistical considerations", Journal of Personality and Social Psychology, Vol 51, pp. 1173-1182.

Bartlett, M. Y. and DeSteno, D. (2006), "Gratitude and prosocial behaviour: Helping when it costs you", Psychological Science, Vol 17, pp. 319-325.

Fleming, P. and Jones, M. T. (2013), The End of Corporate Social Responsibility: Crisis and Critique. London: Sage.

Gouldner, A. W. (1960), “The norm of reciprocity: A preliminary statement", American Sociological Review, Vol 25, pp. 161-178.

Grunig, J. E. (1993), "Image and substance: From symbolic to behavioral relationships", Public Relations Review, Vol 19, pp. 121-139.

Grunig, J. E. and White, J. (1992), “The effect of worldviews on public relations: Theory and practice”, In J.E. Grunig, D.M. Dozier, W.P. Ehling, L.A. Grunig, F.C. Repper, and J. White (Eds.), Excellence in Public Relations and Communication Management (pp. 31-64). New Jersey: Lawrence Erlbaum.

Hart, N. (1995), Strategic Public Relations. London: Macmillan Business Press

Hasan, S. F. e., Lings, I., Neale, L. and Mortimer, G. (2014), "The role of customer gratitude in making relationship marketing investments successful", Journal of Retailing and Consumer Services, Vol 21, pp. 788-796. 
Hoffman, L. and Rovine, M. J. (2007). "Multilevel models for the experimental psychologist: Foundations and Illustrative Examples", Behavior Research Methods, Vol 39, pp. 101-117.

Kitchen, P. J., and Papasolomou, I. (1997), “The Emergence of Marketing PR”, In P.J. Kitchen (Ed.), Public Relations: Principles and practice, 1st ed. (pp. 239-271). London: International Thomson Business Press.

Ledingham, J. A. (2003), "Explicating relationship management as a general theory of public relations", Journal of Public Relations Research, Vol 15, pp. 181-198.

Ledingham, J. A., and Bruning, S. D. (1998), "Relationship management and public relations: Dimensions of an organization-public relationship", Public Relations Review, Vol 24, pp. 5565.

L'Etang, J. (1996), “Corporate responsibility and public relations ethics”, In J. L'Etang and M. Pieczka (Eds.), Critical Perspectives in Public Relations (pp. 54-105). London: International Thomson Business Press.

McCullough, M. E., Emmons, R. A., and Tsang, J. (2002), “The grateful disposition: A conceptual and empirical topography", Journal of Personality and Social Psychology, Vol 82, pp. 112-127.

Morales, A. C. (2005), "Giving firms an "E" for effort: Consumer responses to high-effort firms". Journal of Consumer Research, Vol 31, pp. 806-812.

Morgan, R. M., and Hunt, S. D. (1994), “The commitment-trust theory of relationship marketing", Journal of Marketing, Vol 58, pp. 20-38.

Nezlek, J. (2001), "Multilevel random coefficient analyses of event- and interval- contingent data in social and personality psychology research", Personality and Social Psychology Bulletin, Vol 27, pp. 771-785.

Palmatier, R. W. (2008), Relationship marketing. Marketing Science Institute, Cambridge, MA. 
Palmatier, R. W., Jarvis, C., Bechkoff, J. R., and Kardes, F. R. (2009), "The role of customer gratitude in relationship marketing”, Journal of Marketing, Vol 73, pp. 1-18.

Papasolomou, I., Thrassou, A., Vrontis, D. and Sabova, M. (2014), "Marketing public relations: A consumer-focused strategic perspective", Journal of Customer Behaviour, Vol 13 , pp. 5-24.

Parasuraman, A., Zeithaml, V.A. and Berry, L.L. (1988), "SERVQUAL: a multiple item scale for measuring consumers' perceptions of service quality”, Journal of Retailing, Vol. 64 No.1, pp. 12-40.

Raggio, R. D. and Folse, J. A. D. (2009), "Gratitude works: its impact and the mediating role of affective commitment in driving positive outcomes", Journal of the Academy of Marketing Science, Vol 37, pp. 455-469.

Raggio, R. D. and Folse, J. A. D. (2011), "Expressions of Gratitude in Disaster Management: An Economic, Social Marketing, and Public Policy Perspective on Post-Katrina Campaigns", Journal of Public Policy \& Marketing, Vol 30, No. 2, pp. 168-174.

Raggio, R. D., Walz, A. M., Godbole, M. B., and Folse, J. A. G. (2014), "Gratitude in relationship marketing: Theoretical development and directions for future research", European Journal of Marketing, Vol 48, pp. 2-24.

Ravald, A. and Grönroos, C. (1996), "The value concept and relationship marketing”, European Journal of Marketing, Vol 30, pp. 19-30.

Sirdeshmukh, D., Singh, J., and Sabol, B. (2002), "Consumer trust, value, and loyalty in relational exchanges", Journal of Marketing, Vol 66, pp. 15-37.

Smith, A. (1976), The Theory of Moral Sentiments (6 $6^{\text {th }}$ ed.), Oxford, England: Clarendon Press. (Original work published 1790). 
Snijders, T. A. B. (2005), "Fixed and random effects", In B. S. Everitt and D. C. Howell (Eds.), Encyclopedia of Statistics in Behavioral Science, Vol 2. (pp. 664-665). Chicester: Wiley.

Sobel, M. E. (1982), “Asymptotic intervals for indirect effects in structural equations models", In S. Leinhart (Ed.), Sociological methodology 1982 (pp. 290-312). San Francisco: Jossey-Bass.

Tesser, A., Gatewood, R. and Driver, M. (1968), "Some determinants of gratitude", Journal of Personality and Social Psychology, Vol 9, pp. 233-236.

Trivers, R. L. (1971), “The evolution of reciprocal altruism”, Quarterly Review of Biology, Vol 46, pp. 35-57.

Vargo, S. L. and Lusch, R. F. (2004), "Evolving to a new dominant logic for marketing”, Journal of Marketing, 68, 1-17.

Wood, A. M., Froh, J. J, \& Geraghty, A. W. A. (2010). Gratitude and well-being: A review and theoretical integration. Clinical Psychology Review, Vol 30, pp. 890-905.

Wood, A. M., Maltby, J., Stewart, N., Linley, P. A., and Joseph, S. (2008), “A socialcognitive model of trait and state levels of gratitude", Emotion, Vol 8, pp. 281-290.

Zeithaml, V. A., Berry, L. L., and Parasuraman, A. (1996), “The behavioural consequences of service quality", Journal of Marketing, Vol 60, pp. 31-46. 
Table 1: Manipulation Check of Appraisal Group Manipulation in Study 1: outcomes of initial MANOVA and univariate analyses.

\begin{tabular}{|c|c|c|c|c|}
\hline & \multirow{2}{*}{ MANOVA } & \multicolumn{3}{|c|}{ Univariate ANOVA } \\
\hline & & Desire to help & Cost & Value \\
\hline Appraisal Group & $\begin{array}{c}\mathrm{F}(3,82)=38.3 * * * \\
\eta^{2}=.584\end{array}$ & $\begin{array}{c}\mathrm{F}(1,84)=109.76 * * * \\
\eta^{2}=.566\end{array}$ & $\begin{aligned} \mathrm{F}(1,84) & =75.35 * * * \\
\eta^{2} & =.473\end{aligned}$ & $\begin{array}{c}\mathrm{F}(1,84)=75.83 * * * \\
\eta^{2}=.474\end{array}$ \\
\hline Organisation-type & $\begin{array}{c}\mathrm{F}(3,82)=165.85 * * * \\
\eta^{2}=.859\end{array}$ & $\begin{array}{c}\mathrm{F}(1,84)=398.16 * * * \\
\eta^{2}=.826\end{array}$ & $\begin{aligned} \mathrm{F}(1,84) & =36.71 * * * \\
\eta^{2} & =.304\end{aligned}$ & $\begin{array}{c}\mathrm{F}(1,84)=183.47 * * * \\
\eta^{2}=.686\end{array}$ \\
\hline Vignette & $\begin{array}{c}\mathrm{F}(3,82)=4.49 * * \\
\eta^{2}=.254\end{array}$ & $\begin{array}{c}\mathrm{F}(1,84)=6.81 * * \\
\eta^{2}=.075\end{array}$ & $\begin{array}{c}\mathrm{F}(1,84)=2.50 \S \\
\eta^{2}=.029\end{array}$ & - \\
\hline $\begin{array}{c}\text { Appraisal Group X } \\
\text { Vignette }\end{array}$ & $\begin{array}{c}\mathrm{F}(3,82)=8.27 * * * \\
\eta^{2}=.386\end{array}$ & $\begin{array}{c}F(1,84)=2.92 \S \\
\eta^{2}=.034\end{array}$ & $\begin{array}{c}\mathrm{F}(1,84)=3.51 * \\
\eta^{2}=.040\end{array}$ & $\begin{aligned} \mathrm{F}(1,84) & =8.13 * * * \\
\eta^{2} & =.088\end{aligned}$ \\
\hline $\begin{array}{c}\text { Appraisal Group X } \\
\text { Organisation-type }\end{array}$ & $\begin{array}{c}\mathrm{F}(3,82)=2.80 * \\
\eta^{2}=.093\end{array}$ & $\begin{array}{c}\mathrm{F}(1,84)=3.17 \S \\
\eta^{2}=.036\end{array}$ & - & $\begin{array}{c}F(1,84)=3.85 \S \\
\eta^{2}=.044\end{array}$ \\
\hline $\begin{array}{l}\text { Organisation-type } X \\
\text { Vignette }\end{array}$ & $\begin{array}{c}\mathrm{F}(3,82)=5.55 * \\
\eta^{2}=.297\end{array}$ & $\begin{array}{c}\mathrm{F}(1,84)=3.86 * \\
\eta^{2}=.044\end{array}$ & $\begin{array}{c}\mathrm{F}(1,84)=5.91 * * \\
\eta^{2}=.066\end{array}$ & $\begin{array}{c}\mathrm{F}(1,84)=2.68 \S \\
\eta^{2}=.031\end{array}$ \\
\hline $\begin{array}{c}\text { Appraisal Group X } \\
\text { Organisation-type X } \\
\text { Vignette }\end{array}$ & $\begin{array}{c}\mathrm{F}(3,82)=5.62 * * * \\
\eta^{2}=.299\end{array}$ & $\begin{array}{c}\mathrm{F}(1,84)=7.54 * * \\
\eta^{2}=.082\end{array}$ & - & $\begin{array}{c}\mathrm{F}(1,84)=7.41 * * \\
\eta^{2}=.081\end{array}$ \\
\hline
\end{tabular}

$p<.001 * * *, p<.01 * *, p<.05^{*}, p<.1 \S$

$\mathrm{N}=86$ (data for perceptions of value for one vignette was missing for one participant in the high appraisal condition). 
Table 2: Manipulation Check of Appraisal Group Manipulation in Study 1: outcomes of Bonferroni-corrected $(p=.008) t$-tests in Study 1 . Means $(M)$ and standard deviations (in parentheses) are also shown for the two benefit appraisal groups.

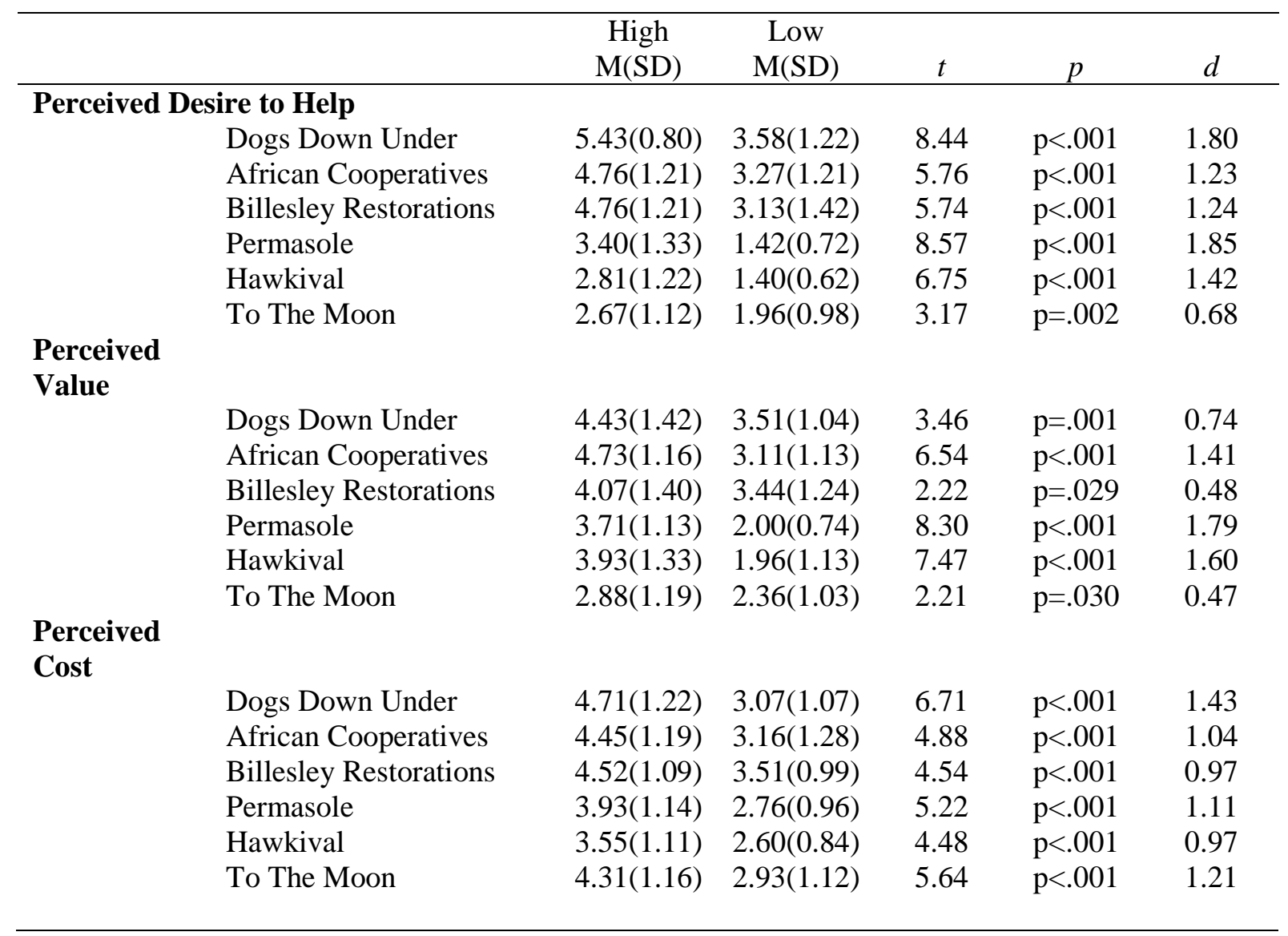


Table 3: Manipulation Check of Appraisal Group Manipulation in Study 2: outcomes of MANOVA and univariate analyses for Study 2.

\begin{tabular}{|c|c|c|c|c|}
\hline & MANOVA & Desire to help & Cost & Value \\
\hline Appraisal Group & $\begin{array}{c}\mathrm{F}(3,61)=13.01 \\
* * * \eta^{2}=.390\end{array}$ & $\begin{array}{c}\mathrm{F}(1,63)=24.50 \\
* * * \eta^{2}=.280\end{array}$ & $\begin{array}{c}\mathrm{F}(1,63)=20.30 \\
* * * \eta^{2}=.244\end{array}$ & $\begin{array}{c}\mathrm{F}(1,63)=37.68 \\
* * * \eta^{2}=.374\end{array}$ \\
\hline $\begin{array}{l}\text { Appraisal Group } \\
\text { X Organisation- } \\
\text { type }\end{array}$ & $\begin{array}{c}\mathrm{F}(3,61)=4.79 \\
* * \eta^{2}=.191\end{array}$ & - & $\begin{array}{l}\mathrm{F}(1,63)=8.00 \\
* * \eta^{2}=.113\end{array}$ & - \\
\hline
\end{tabular}


a

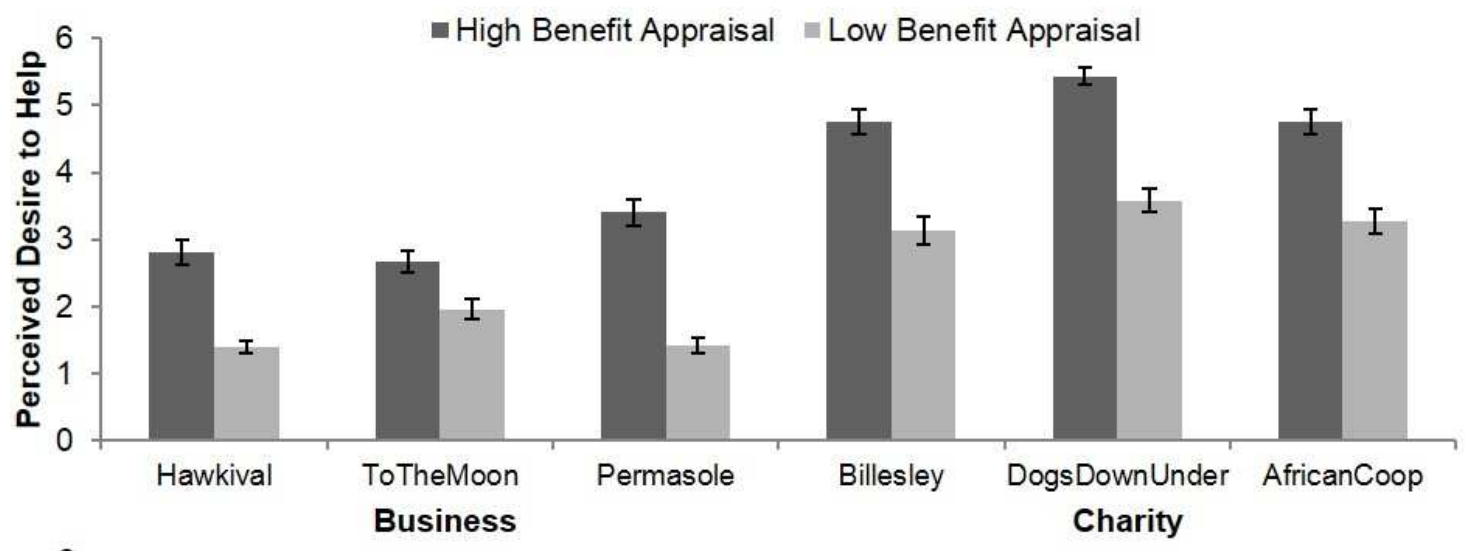

b

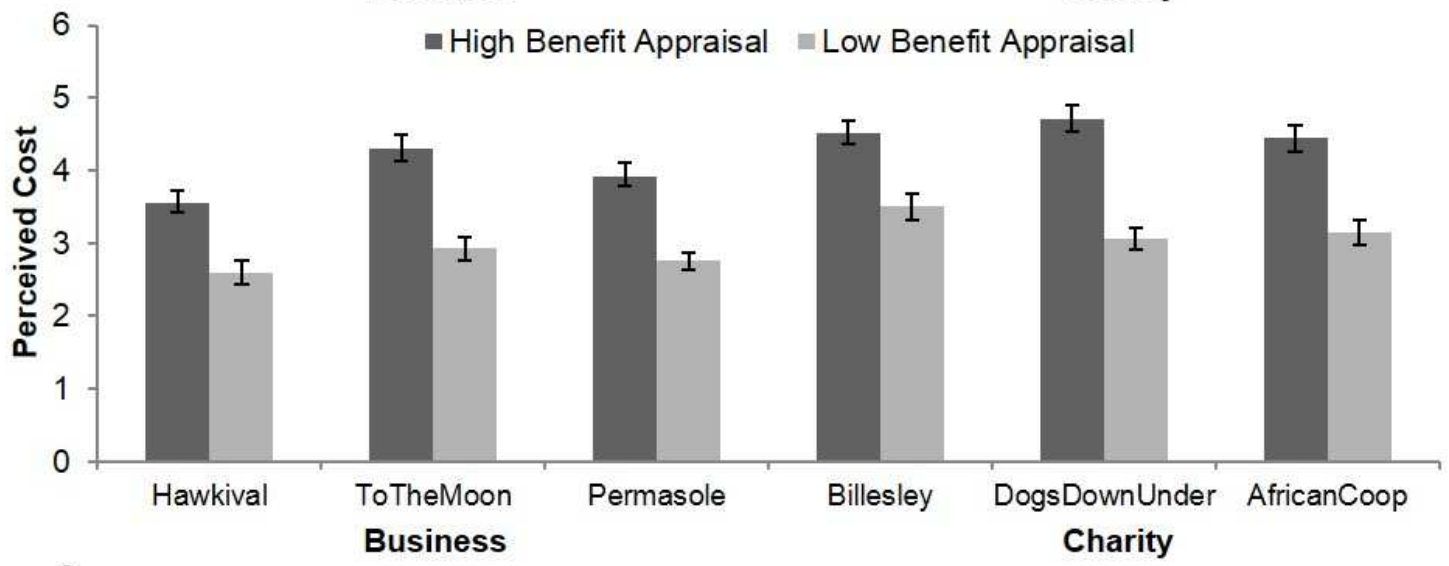

C

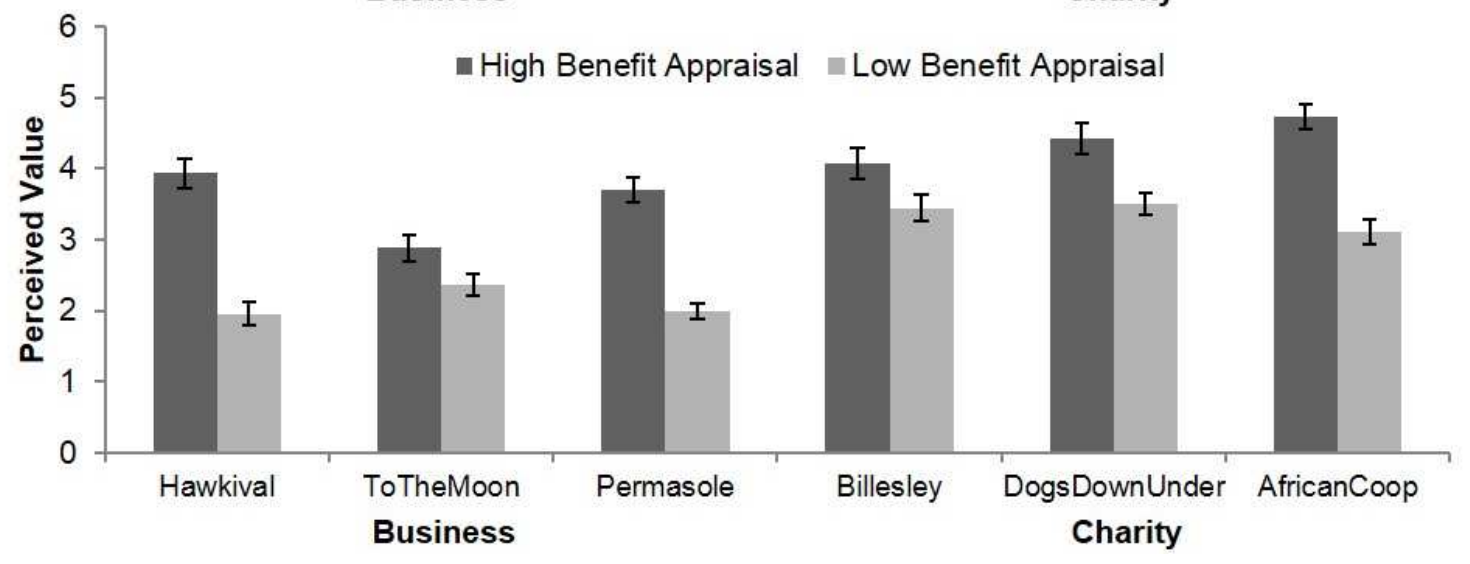

Figure 1: Mean perceptions of genuine desire to help (Figure 1a), cost to organisation (Figure

1b) and value of services (Figure 1c) split according to appraisal condition, organisation-type and vignette in Study 1. Error bars show $+/-1$ standard error. 


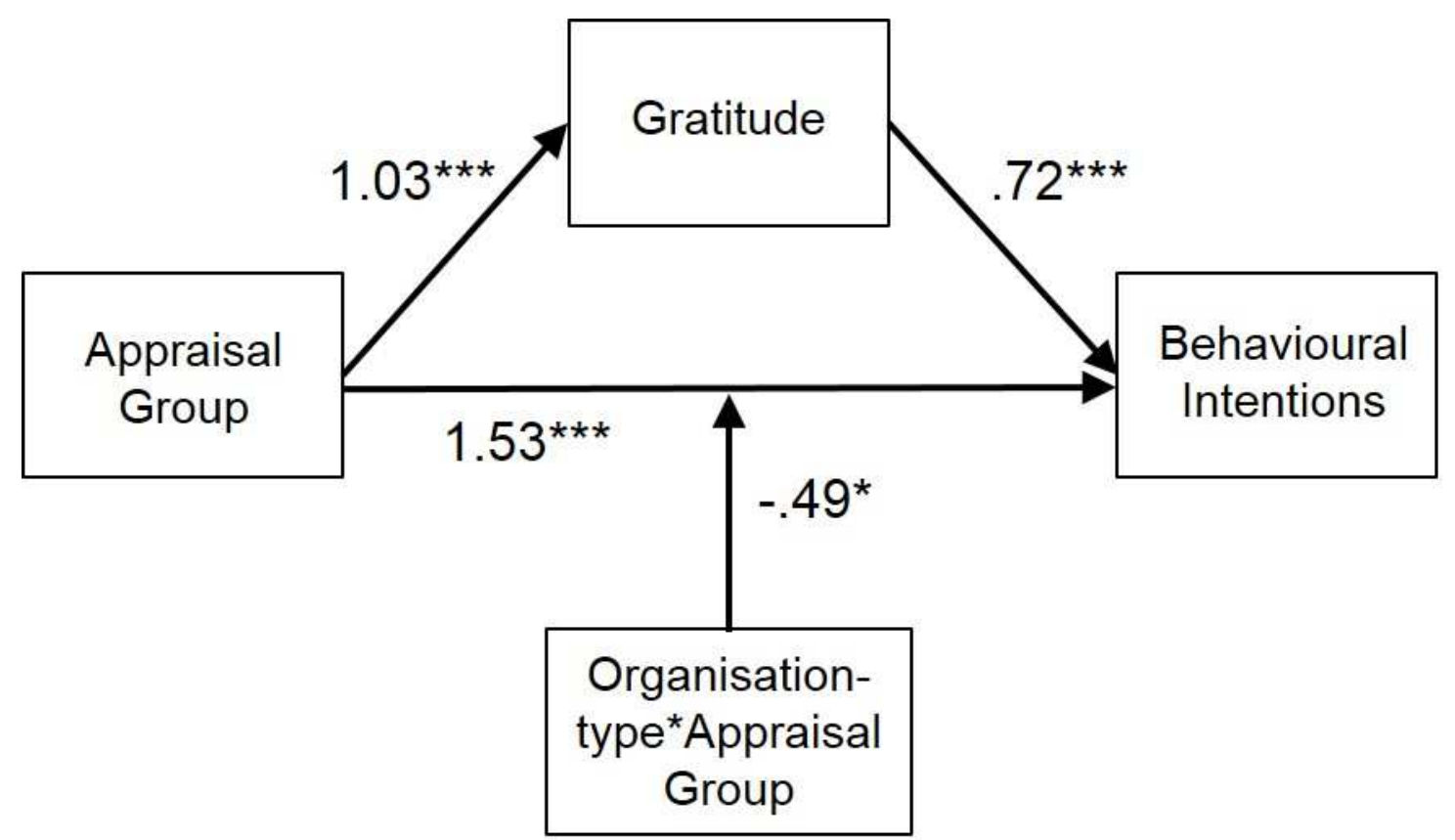

Figure 2: Diagram showing the outcomes of multilevel model analyses describing the relationship between appraisal group, gratitude and behavioural intentions, alongside the moderation of the direct pathway by organisation-type in Study 1. Note that the $b$ for the direct impact of appraisal group on behavioural intentions when gratitude (and associated interaction term) are removed was 2.18 , indicating that gratitude mediated $53 \%$ of this pathway. $* * * p<.001, * * p<.01, * p<.05$. 

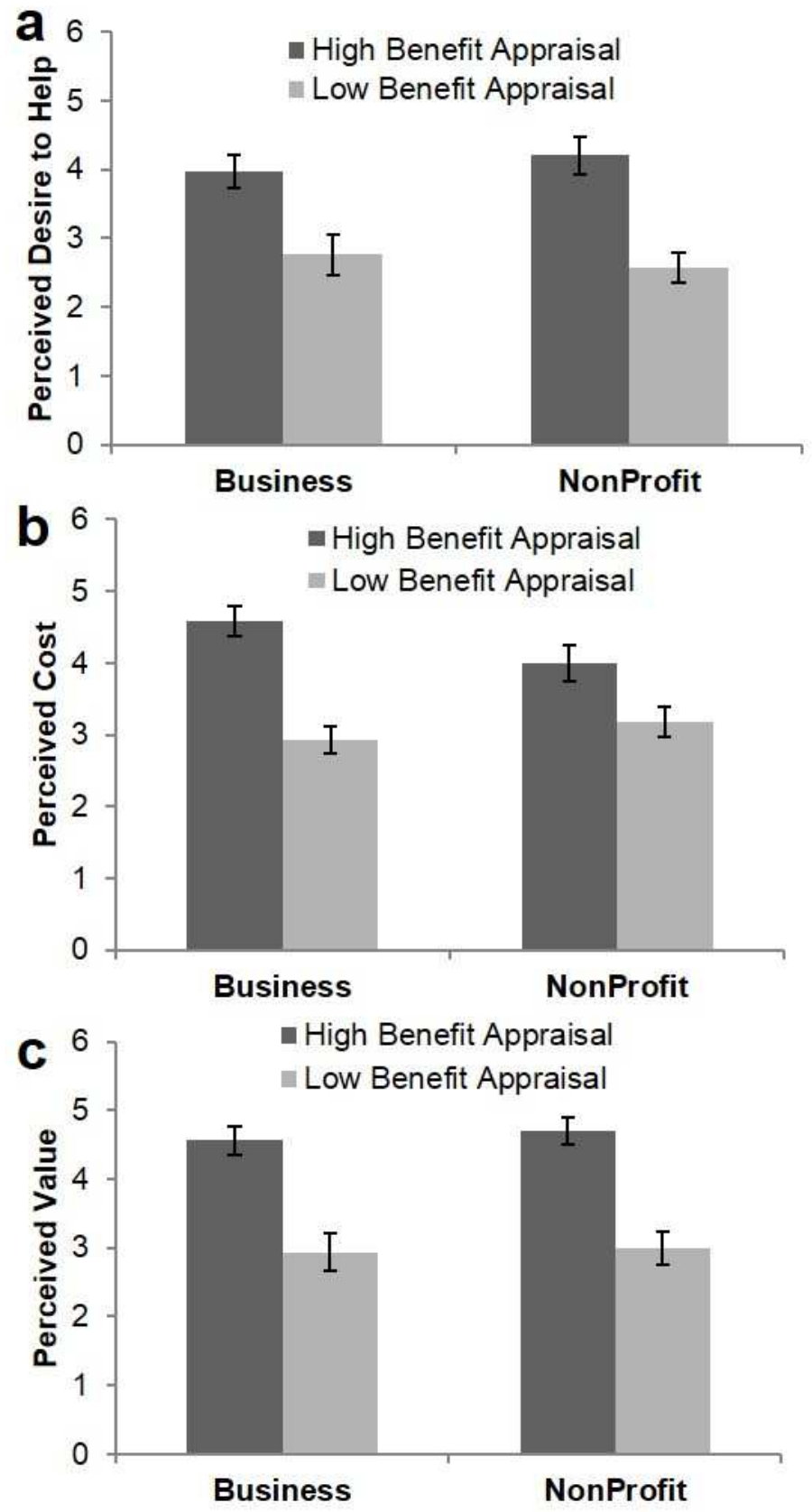

Figure 3: Mean perceptions of genuine desire to help (Figure 3a), cost to organisation (Figure 3b) and value of services (Figure 3c) split according to appraisal condition and organisationtype in Study 2. Error bars show +/- 1 standard error. 


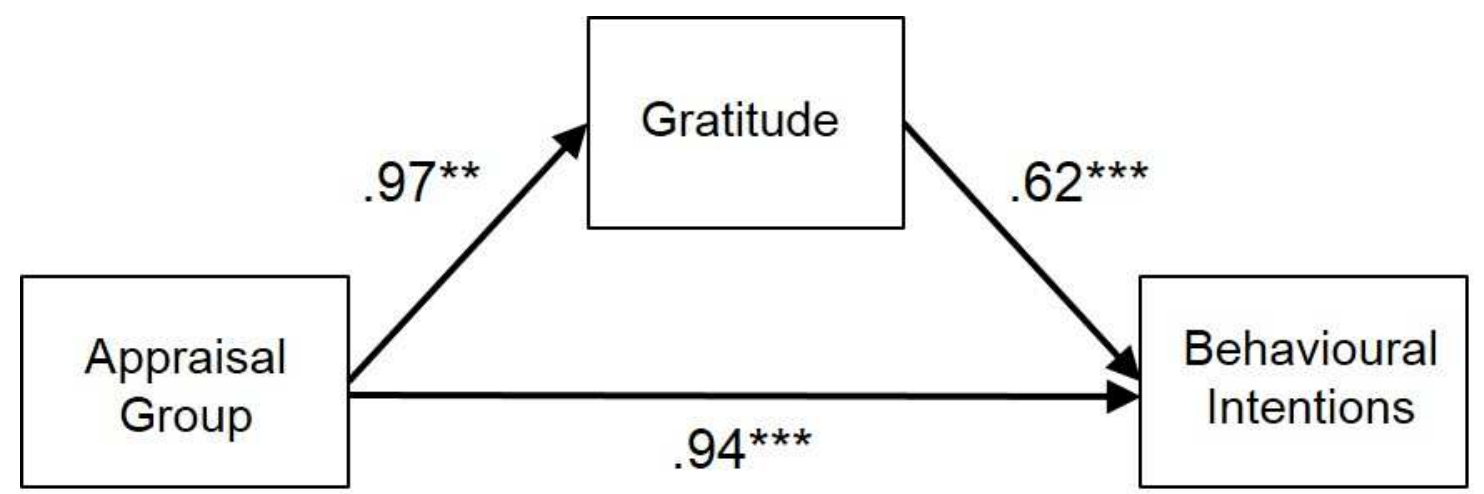

Figure 4: Diagram showing the outcomes of multilevel models describing the relationship between appraisal group, gratitude and behavioural intentions in Study 2. ***p $<.001$, $* * p<.01, * p<.05$. 


\section{Appendix A: Text for High and Low Appraisal Group in Study 1 (1-3 describe businesses; 4-6 describe charities)}

A (High): Hawkival is a software company that provides antivirus protection. Hawkival software is state of the art and provides protection against a host of computer attacks, including viruses, spyware, phishing and identity theft. Hawkival provide a 1-year free service to new customers because they want to help protect all internet users. Hawkival spend a great deal of resources on the continuous training of their programmers to keep on top of the technological advances of virus writers.

(Low): Hawkival is a software company that provides antivirus protection. Hawkival software provides protection against most standard viruses but does not go beyond the protective systems and firewalls that come free with most new computers. Hawkival provide a 1-year free service to new customers because they want to entice them to their brand. Hawkival do not spend much on the training of their programmers to keep on top of the technological advances of virus writers.

B (High): To The Moon Ltd is a travel company that sells and organises tailor-made travel experiences and holidays. To The Moon seeks to ensure that a holiday should be exactly what the customer wants and not limited to packages that already exist. To The Moon customers receive their own personal agent who is contactable 24 hours a day because the company is $100 \%$ committed to customising service. To The Moon staff often dedicate many working weeks and multiple resources and contacts to creating the customers' chosen holiday.

(Low): To The Moon Ltd is a travel company that sells and organises tailor-made travel experiences and holidays. To The Moon offers bespoke holiday experiences but most customers usually end up choosing from a standard set of holiday options. To The Moon provides customers with a personal agent who is contactable 24 hours a day in order to provide the appearance of top personalised service. Staff working at To The Moon do not dedicate any more time to their customers than those working at travel companies offering standard package holidays.

C (High): Permasole is a high street retailer that sells hiking shoes with a lifetime guarantee. Permasole shoes are designed to protect customers on every adventure, be it their first or their ninety-first. Permasole provides a lifetime guarantee because it truly cares about providing the maximum experience in comfort and will replace any product the minute it becomes damaged or uncomfortable. Permasole prides itself on this lifetime guarantee even though it can risk substantial costs to its bottom line.

(Low): Permasole is a high street retailer that sells hiking shoes with a lifetime guarantee. Permasole shoes are designed to look good rather than endure and often do not last more than a few years. Permasole provides a lifetime guarantee because it cares predominantly about appearing to provide service that fits with the company's branding. Permasole is a subsidiary of a larger company who can easily cover the costs incurred by multiple claims on the lifetime guarantee.

D (High): Billesley Restorations is a charity dedicated to the restoration of historical manuscripts. Many of these documents are of considerable personal and historical value to families who send them in, and skilled technicians help preserve them for future generations. 
Billesley Restorations was set up in 1984 by patron Derek Billesley when he realised no facilities for the public to preserve their family history were available. Mr Billesley has dedicated his life savings and 10 years of his life to setting up the charity to help achieve this.

(Low): Billesley Restorations is a charity dedicated to the restoration of historical manuscripts. The charity's technicians help preserve documents although technological advances mean many people are able to permanently preserve their family history in digital format at home themselves. Billesley Restorations was set up in 1984 by patron Derek Billesley, an amateur archivist, because he wanted to immortalise his name in British historical archives. Mr Billesley is a very wealthy man who is easily able to afford the foundation of the charity.

E (High): Dogs Down Under is a charity that takes care of dogs in Australia. The organisation takes care of dogs that have suffered from cruelty or neglect in the past and provides them with shelter, companionship and veterinary care for as long as they need. Dogs Down Under is staffed by dog lovers who want to create a world where dogs live free from suffering. Unpaid volunteers work hard to achieve this and often give up most or all of their free time to take care of the rescued dogs.

(Low): Dogs Down Under is a charity that takes care of dogs in Australia. The organisation provides dogs with shelter and companionship for the short time it takes before they are permanently homed. Dogs Down Under is mainly concerned with keeping dogs off the streets rather than improving dog welfare. Volunteers like to spend time helping out at the charity centre because it means they get to spend an hour a week playing with puppies and young dogs for free.

F (High): African Cooperatives is a charity, working to improve the lives of people in Africa by supporting cooperatives within communities in Eastern Africa. Many new cooperatives in Africa have greatly benefitted from the strategic guidance and training provided by experienced UK volunteers. African Cooperatives volunteers get involved because they genuinely want to help local cooperatives get up and running. Most volunteers have worked many months to be able to afford the necessary travel and accommodation expenses to be able to contribute to this work.

(Low): African Cooperatives is a charity, working to improve the lives of people in Africa by supporting cooperatives within communities in Eastern Africa. Many locals in Africa have managed to build successful cooperative projects on their own without outside help from volunteers. UK volunteers get involved with African Cooperatives simply because of the once-in-a-lifetime experience that volunteering in Africa can offer. Most volunteers are relatively wealthy and can easily afford the necessary travel and accommodation expenses. 


\section{Appendix B: Text for High and Low Appraisal Group in Study 2}

\section{High Benefit Appraisal}

Hawklin is a business/non-profit organisation that provides antivirus protection. Hawklin software is state of the art and provides protection against a host of computer attacks, including viruses, spyware, phishing and identity theft. Hawklin provide a 1-year free service to new customers because they want to help protect all internet users. Hawklin spend a great deal of resources on the continuous training of their programmers to keep on top of the technological advances of virus writers.

AfriCo is a business/non-profit organisation working to improve the lives of people in Africa by supporting cooperatives within communities in Eastern Africa. Many new cooperatives in Africa have greatly benefitted from the strategic guidance and training provided by AfriCo staff. AfriCo's UK workers get involved because they genuinely want to help local cooperatives get up and running. Most AfriCo workers are required to work long hours for many months on low pay to be able to contribute to this work.

\section{Low Benefit Appraisal}

Hawklin is a business/non-profit organisation that provides antivirus protection. Hawklin software provides protection against most standard viruses but does not go beyond the protective systems and firewalls that come free with most new computers. Hawklin provide a 1-year free service to new customers because they want to entice them to their brand. Hawklin do not spend much on the training of their programmers to keep on top of the technological advances of virus writers.

AfriCo is a business/non-profit organisation working to improve the lives of people in Africa by supporting cooperatives within communities in Eastern Africa. Many locals in Africa have managed to build successful cooperative projects on their own without outside help. AfriCo's UK workers get involved because of the once-in-a-lifetime experience that working in Africa can offer. Most AfriCo workers come from wealthy backgrounds and can easily afford to work for many months on low pay to be able to contribute to this work. 